\title{
INDUSTRIALIZACIÓN Y DESARROLLO EN LA ARGENTINA POS-“WASHINGTON CONSENSUS": UN ABORDAJE CRÍTICO DESDE LA PERSPECTIVA SECTORIAL, ACTORAL Y ESPACIAL*
}

Recibido: 7 de mayo de 2014 Aprobado: 18 de agosto 2015

\author{
Carolina T. Lauxmann** \\ Víctor Ramiro Fernández ${ }^{* * *}$
}

\section{RESUMEN}

Argentina, en 2001, luego de experimentar una de las crisis más profunda de su historia, consecuencia de la primacía de las políticas neoliberales durante la década de 1990 y de los resultados negativos en términos de crecimiento y desigualdad socio-espacial a que estas dieron lugar, comenzó a reconsiderar el rol del Estado en la economía. En dicho contexto se lo sindicó como un actor estratégico para dinamizar un crecimiento inclusivo que viabilice el desarrollo. La promoción estatal a la actividad industrial ocupó un lugar central en la consecución de dicho objetivo. Transcurrida ya más de una década, en el presente trabajo se demuestra, a través del análisis de estadísticas oficiales, cómo la re-intervención del Estado poco ha podido hacer para avanzar en la conformación de un tejido industrial complejo, dinámico y descentralizado -actoral y espacialmente-, que permita viabilizar el desarrollo

\section{PALABRAS CLAVE}

Industria, Estado, desarrollo económico, Argentina.

\section{CLASIFICACIÓN JEL}

O10; P10

\section{CONTENIDO}

Introducción; 1. La industria como motor del desarrollo "nacional"; 2. La industria pos-crisis de 2001. Sectores, actores y espacios privilegiados del crecimiento industrial; 3. Consideraciones finales; Bibliografía.

* $\quad$ El presente trabajo forma parte de los resultados de investigación alcanzados en el marco del desarrollo del PACT titulado "Capacidades estatales y políticas de desarrollo productivo en la Argentina reciente (1990-2012): perspectivas comparadas y multi-escalares", financiado por la Universidad Nacional del Litoral y con período de ejecución entre 2013-2016. Algunos avances provisorios vinculados a esta problematización fueron presentados en las I Jornadas Interdisciplinares del ISHIR Conicet.

** Doctoranda en Ciencias Sociales (Universidad de Buenos Aires) con beca del Consejo Nacional de Investigaciones Científicas y Técnicas (CONICET), Argentina. Magíster en Histórica Económica y Política Económica, FCE-UBA. Miembro del equipo de investigación del Instituto de Investigación Estado Territorio y Economía (www.iiete.unl.edu.ar) de la UNL, Santa Fe, Argentina, y profesora de dicha casa de estudios. Dirección postal: Urquiza 3164. Teléfono: +54 9 (342) 548-7075. Correo electrónico: claux@unl.edu.ar.

*** Doctor en Ciencias Políticas (Universidad Autónoma de Madrid). Magister en Ciencias Sociales (Sociología) FLACSO Programa Argentina. Pos-doctorado en las Universidades de Durham (Reino Unido) y British Columbia (Canadá). Investigador del Consejo Nacional de Investigaciones Científicas (CONICET), Argentina y Profesor titular de la Universidad Nacional del Litoral, Santa Fe, Argentina, donde dirige el Instituto de Investigación Estado, Territorio y Economía (www.iiete.unl.edu.ar). Dirección postal: Pedro Díaz Colodrero 2462Teléfono: +54 (342) 4810446. Correo electrónico: rfernand@fcjs.unl.edu.ar. 


\title{
INDUSTRIALIZATION AND DEVELOPMENT IN POST-“WASHINGTON CONSEN- SUS" ARGENTINA: A CRITICAL APPROACH FROM SECTORIAL, SPATIAL, AND AGENT'S PERSPECTIVE
}

\section{ABSTRACT}

Argentina, in 2001, after going through one of the deepest crisis of its history, a consequence of neoliberal policies during the 90s and negative results in terms of growth and social spatial inequality- started reconsidering the role of the State, in economy. In such a context, the role of the State was considered as a strategic actor for energizing an inclusive growth, which makes development viable. State promotion to industrial activity occupied a central place in such an objective. Now after more than a decade, this research shows, through statistical analysis of official statistics, how State's re-invention has made little for advancing in the formation of a complex, industrial, dynamic, and decentralized tissue, -spatially and with agents-, which allows visualizing the development.

\section{KEY WORDS}

Industry, State, economic development, Argentina.

JEL CLASSIFICATION

O10; $\mathrm{P} 10$

\section{CONTENT}

Introduction; 1. The industry as a motor of national development; 2. 2001 Post-crisis industry. Industrial growth privileged sectors, actors, and spaces; 3 . Final considerations; Bibliography.

\section{INDUSTRIALIZAÇÃOEDESENVOLVIMENTONAARGENTINAPÓS-“WASHINGTON CONSENSUS": UMA ABORDAGEM CRÍTICA DESDE A PERSPECTIVA SETORIAL, CONDUTA E ESPACIAL}

\section{RESUMO}

Na Argentina, no ano de 2001, após passar por uma das crises mais profundas em sua história, como um resultado da primazia das políticas neoliberais durante a década de 90 e o resultado negativo em termos de crescimento e desigualdade -sócio-espacial - a que essas deram lugar, começou a repensar o papel do Estado na economia. Neste contexto é o síndico como um ator estratégico para energizar um crescimento inclusivo conducente ao desenvolvimento. A promoção para a atividade industrial tinha ocupado um lugar central para a concretização deste objetivo. Depois de mais de uma década atrás, no presente trabalho é apresentado, através da análise das estatísticas oficiais, tais como a re-intervenção do Estado foi capaz de fazer muito pouco para o avanço da criação de um tecido industrial complexo, dinâmico e descentralizado -conduta e espacialmente-, que permitem viabilizar o desenvolvimento.

\section{PALAVRAS-CHAVE}

Indústria, Estado, desenvolvimento econômico, Argentina.

\section{CLASSIFICAÇÃO JEL}

\author{
O10; P10
}

\section{CONTEÚDO}

Introdução; 1. A indústria como um motor de desenvolvimento nacional; 2. A indústria pós-crise de 2001 Os setores, atores e espaços privilegiados do crescimento industrial; 3. Considerações Finais; bibliografia. 
Industrialización y desarrollo en la Argentina pos-"washington consensus": un abordaje crítico desde...

\section{INTRODUCCIÓN}

Los problemas del desarrollo de Argentina alcanzaron una marcada visibilidad en el escenario crítico que atravesó el país sobre finales del siglo pasado, e inicios del presente. Consecuencia de la primacía de políticas neoliberales durante la década de 1990, se vieron agudizados en el territorio nacional los procesos de dependencia y marginación, y las inequidades socio-espaciales propias de la condición periférica -subdesarrollada- de estas latitudes. En dicho contexto, comenzaron a emerger reacciones que cuestionaban y rechazaban los postulados básicos del neoliberalismo. Las alternativas políticas que llegaron al Estado luego de la crisis de 2001 proponían una agenda neo-desarrollista (ver por ejemplo Bresser-Pereira, 2006; 2007; Gaitán, 2014) en la que recuperaban la importancia del Estado, actuando vis a vis el mercado, para motorizar desde adentro el crecimiento, y morigerar las desigualdades existentes en los niveles social y espacial. El impulso de la actividad industrial pasó a ocupar en el discurso oficial un lugar clave para lograr este cometido (Ministerio de Industria, 2012; MPFIPS; 2006). Con la (re)industrialización no solo se procuraba: a) recomponer el entramado productivo del país, fuertemente afectado por la aplicación del ideario neoliberal (Azpiazu y Schorr, 2010; Schorr, 2004), y avanzar en hacer más complejo y sofisticado del mismo, de modo tal de sentar las bases para cualificar las condiciones de reproducción social interna y de inserción internacional; también, se pretendía, b) superar los históricos desequilibrios existentes en el interior del territorio nacional, igualmente agudizados durante la etapa neoliberal (Cao y Vaca, 2006; Manzanal, 1995; Rofman, 1999), al fortalecer las capacidades productivas manufactureras locales.

Ahora bien, aunque es cierto que la industria es considerada una actividad estratégica para impulsar el desarrollo', y que desde la salida de la crisis de 2001 esta ha recuperado participación dentro de la generación de valor agregado de la economía argentina, y ha recobrado también cierto dinamismo en la generación de empleo (Azpiazu y Schorr, 2010; Coatz y Kosacoff, 2012; Fanelli, 2012; Schorr, 2012), ¿hasta qué punto este re-posicionamiento de las manufacturas en el centro de la escena ha tendido a viabilizar el desarrollo "nacional"? Es decir, cla industria argentina ha experimentado, de la mano de la intervención del Estado, una recuperación que

1 Diversos autores, desde diferentes perspectivas, han referido a lo largo de la historia a la importancia de la actividad manufacturera como herramienta estratégica para el desarrollo dentro del sistema capitalista. Actualmente, una voluminosa y a su vez reconocida producción académica plantea la centralidad del sector industrial para viabilizar el desarrollo, al mismo tiempo que advierte la importancia de la política pública para impulsar el desenvolvimiento de aquel; ver por ejemplo: Cohen, y Zysman, (1987), Chang (2004), Chibber (2003), Hausmann y Rodrik (2003), Kohli (2004), Rodrik (2004), Reinert (2006), Hausmann, Rodrik y Sabel (2008), Wade (2012) y Reiner y Starizt (2013). 
permita sentar las bases para generar un proceso de crecimiento inclusivo actoral y espacialmente dentro del territorio nacional?

Procurando dar respuesta a este interrogante, organizamos el presente trabajo en tres apartados. En el primero de ellos planteamos la importancia de la actividad industrial y las formas que debería presentar la misma para permitir un mejoramiento de las condiciones de reproducción social interna y una cualificación de las formas de inserción internacional. En el segundo analizamos la evolución de la actividad manufacturera en el país desde la salida de la convertibilidad hasta la actualidad, centrándonos en las características estructurales del sector y su incidencia en el dinamismo de las distintas regiones del país. En el tercer apartado, sobre la base de los desarrollos de los puntos 1 y 2, presentamos una breves consideraciones finales respecto a si la actividad industrial ha logrado posicionarse como motor central para propulsar el desarrollo nacional o, si, por el contrario, se trata de un episodio más de crecimiento desequilibrado del sector que margina a actores económico-sociales y concentra el dinamismo en estrechos márgenes territoriales.

\section{LA INDUSTRIA COMO MOTOR DEL DESARROLLO NACIONAL}

La importancia de la actividad manufacturera no es algo nuevo en la agenda de desarrollo latinoamericano. Los teóricos estructuralistas, a mediados del siglo pasado, comenzaron a reparar en la necesidad de conformar un sector industrial endógeno, complejo y sofisticado, capaz de generar importante valor agregado, que permita dinamizar la economía y viabilizar el desarrollo (CEPAL, 2012). Entendían que la diferencia entre centros - desarrollados y periferias -subdesarrolladas respondía a la capacidad diferencial de unos y otros para generar y apropiarse de los frutos del progreso técnico. El hincapié en el desenvolvimiento del sector industrial residía en la consideración de que la actividad manufacturera era la que, por excelencia, para su desenvolvimiento, y a partir del mismo, demandaba y difundía el progreso técnico y la innovación al conjunto del entramado productivo. De este modo, al incentivar el desarrollo del sector se reduciría, entonces, la brecha tecnológica $-\mathrm{y}$ de ingreso de ella derivada- existente con los centros, lo que habilitaría a salir de posicionamientos periféricos ${ }^{2}$ (Prebisch, 1983, 1986; 2008; Gurrieri, 2011).

El planteamiento estructuralista era inobjetable en el nivel teórico. Sin embargo, los procesos de industrialización llevados a cabo por diversos Estados latinoamericanos a mediados del siglo XX, inspirados en buena parte en dicho pensamiento,

2 Es necesario reconocer el estructuralismo latinoamericano no ahondaba en cómo debería ser la plasmación espacial de dicho desarrollo industrial -ni planteaba estrategias concretas para ello- de modo de revertir, no sólo las asimetrías con los países centrales, sino las grandes inequidades existentes al interior de los países periféricos, que, en definitiva, respondían a las mismas causas de diferenciación. 
Industrialización y desarrollo en la Argentina pos-" washington consensus": un abordaje crítico desde...

no alcanzaron los resultados esperados. Las particulares características que adoptó la industrialización sustitutiva de importaciones (ISI) no permitieron romper con las asimetrías tecnológicas y de ingresos que los países de estas latitudes mantenían con los países centrales (ver por ejemplo: Fanjzylber, 1983; 1992; Sunkel, 1970; Preston, 1999).

En lo que respecta al caso argentino, si bien la ISI propició la diversificación y sofisticación del tejido industrial, aún a pesar de mantener una fuerte concentración en actividades asociadas a la explotación de recursos naturales, no permitió disminuir la brecha de productividad existente con los países centrales y dinamizar, con cierta endogeneidad, el desarrollo de las fuerzas productivas locales (Azpiazu, 1997; Notchteff, 1998; Schorr, 2004; Ferrer, 2007; Rapoport, 2000; Schvarzer, 1996). El desenvolvimiento del sector industrial pivoteó en torno a actividades manufactureras de baja sofisticación y complejidad vinculadas al procesamiento de recursos naturales, y estaba sustentado por un pequeño grupo de grandes actores -en los que el capital extranjero ocupó un lugar creciente conforme avanzaba el proceso de ISI-que desplegaba comportamientos rentistas ${ }^{3}$-al amparo de posicionamientos monopólicos y/u oligopólicos-, que no permitieron disminuir el diferencial tecnológico y de ingreso existente con los países centrales (Ferrer, 2007; Schvarzer, 1996).

Por otra parte, el emplazamiento geográfico de la producción manufacturera, por el tipo de actividades que primaban en el sector-asociadas, como mencionáramos precedentemente, a la producción de bienes desarrollados sobre la base de explotación de los recursos naturales ${ }^{4}$-, revistió una fuerte concentración en la zona de la pampa húmeda. Esta región, además de contener las fuentes de abastecimiento, concentraba el grueso de la población del país -que haría de mercado de consumoy exhibía el mayor grado de "penetración y predominio capitalista" en el país (Manzanal, 1995), por lo que se encontraba en condiciones de brindar las infraestructuras y los servicios necesarios para sustentar la acumulación.

Por lo tanto, no solo la dinámica sectorial y actoral del proceso de ISI falló en disminuir el diferencial de productividad e ingresos existente con los países centrales. La particular distribución espacial del desarrollo industrial tampoco resultó ser un elemento estratégico para moderar los históricos desequilibrios internos, entre las zonas centrales y las periféricas, a que había dado lugar la incorporación de la Argentina como exportadora de productos agropecuarios al concierto económico

3 Las prácticas rentistas se encuentran asociadas al cortoplacismo; la aversión al riesgo, a la reticencia a incorporar progreso técnico, a desarrollar innovaciones tecno-productiva y/o cualificaciones de la propia gestión, etc. (Azpiazu, 1997; Fajnzylber, 1992; Notchteff, 1998; Schorr, 2004).

4 Las actividades más destacadas en este contexto eran: la producción de alimentos y bebidas, textiles, y alguna maquinaria sencilla. 
mundial"; antes bien, terminó reforzando un proceso de "causaciones acumulativas circulares negativas" (Myrdal, 1959) que bloquea opciones más integradas de desarrollo.

Así, el proceso de industrialización por sustitución de importaciones, que en principio se presentaba como "la cura a los males" de la periferia latinoamericana, terminó agudizando los mismos. La incapacidad de la ISI para reducir las brechas de productividad e ingreso, existentes con los países centrales y entre las distintas regiones de un mismo país, se plasmó, según la terminología empleada por Fajnzylber (1983), en un proceso de "industrialización trunca", que habilitó a un viraje en la política económica que tendió a des-implicar al Estado del estímulo y la protección industrial. Los procesos de ajuste estructural que tuvieron lugar en la periferia latinoamericana y, particularmente, en Argentina ${ }^{6}$, desde mediados de la década de 1970, bajo el proyecto político e ideológico neoliberal, habilitaron una re-estructuración regresiva del aparato productivo industrial, con graves consecuencias socio-económicas (Arceo, 2011; Azpiazu y Schorr, 2010; Schorr, 2004), y socioespaciales, que agudizaron las históricas asimetrías territoriales (Cao y Vaca, 2006; Manzanal, 1995; Rofman, 1999) y reforzaron el posicionamiento periférico del país.

Luego de varios años de primacía de políticas neoliberales y de los efectos, económica, social y espacialmente perniciosos de las mismas, la necesidad de redinamizar el crecimiento, de manera sostenida y con características inclusivas, ha vuelto a poner en el centro de la escena la forma de implicación del Estado en los procesos de desarrollo.

En América Latina, en general, y en Argentina, en particular, han surgido ciertas voces que, desde una perspectiva neo-desarrollista, rescatan algunos de los postulados centrales del estructuralismo latinoamericano. En este sentido, enfatizan la relevancia de la industria para impulsar un crecimiento inclusivo -tanto a nivel actoral como espacial-y sostenible en el tiempo, que viabilice el desarrollo?

Lejos del anacronismo, este esfuerzo por re-posicionar el papel de la industria en el desarrollo ha mostrado cobrar creciente relevancia. Pese a la vigencia de planteamientos teóricos que -inspirados en los pioneros trabajos de Bell (1973) y

5 A este respecto, es importante mencionar que se aplicaron diferentes políticas estatales de fomento industrial en áreas no centrales (Cao y Vaca, 2006), pero no se pudo romper con las tendencias concentradoras a que llevaba la dinámica de acumulación capitalista en las periferias (De Mattos, 1979).

6 Argentina se posicionó como poster-child de las reformas neoliberales (Evans, 2004).

7 El reconocimiento de la importancia de la industria para el dinamismo, la sostenibilidad y la inclusión del crecimiento no resulta propiedad exclusiva de estas latitudes, a escala global puede advertirse la emergencia de un "nuevo consenso heterodoxo" que enfatiza en la importancia de las manufacturas como herramienta estratégica para recomponer el dinamismo del crecimiento económico y garantizar el bienestar de una amplia mayoría de la población mundial (Fernández y Lauxmann, 2014). 
Kutznetz (1971) - destacan la tendencia irreversible hacia la conformación de una sociedad posindustrial, centrada en el dinamismo de los servicios asociados a la generación de tecnología y conocimiento, la actividad manufacturera permanece cumpliendo un papel estratégico para lograr una transformación productiva que permita reducir el diferencial tecnológico y de ingreso existente con los países centrales (ver por ejemplo: Alterburg, 2011; Greenwald y Stiglitz, 2006; Hausmann y Rodrik, 2003; Hausmann, Rodrik y Sabel, 2008). Dicha actividad opera como dinamizadora de la innovación y el conocimiento, en la medida que demanda, para su desenvolvimiento, un constante desarrollo de nuevas técnicas, procesos y/o productos, a fin de mantenerse en la frontera tecnológica y ser competitiva internacionalmente. Estos requerimientos no solo involucran al sector industrial, sino que generan vínculos -hacia atrás y hacia adelante- que impulsan al desarrollo de otros sectores. Las manufacturas, entonces, motorizan el crecimiento económico, al promover el desarrollo de innovaciones en el conjunto del sistema productivo, impulsándolo a posicionarse en la frontera tecnológica mundial, y habilitándolo a la obtención de beneficios extraordinarios de privilegio por tal posición (Cohen y Zysman, 1987; Greenwald y Stiglitz, 2006; Helper, Krueser y Wial, 2012).

Pero, como ha evidenciado la experiencia histórica latinoamericana, y advierte una vasta literatura (ver por ejemplo Arrighi, Silver y Brewer, 2003; Hausmann y Rodrick, 2003; Amsden, 2004; Arceo, 2005; Fajnzylber, 1983,1992; Furtado, 1974), no cualquier tipo de desarrollo industrial propicia dicha dinámica innovadora virtuosa, que permite disminuir los diferenciales de productividad e ingreso existentes con los países centrales y las asimetrías presentes en los diferentes espacios nacionales.

Para incrementar la productividad de la economía y adquirir competitividad internacional en sectores dinámicos que permitan cualificar la forma de inserción en el mercado mundial, es necesario que los sectores de actividad que se estimulen demanden un importante grado de sofisticación tecnológica, importen complejidad -en términos de interrelación productiva-, y que los actores que los motoricen desarrollen comportamientos innovativos schumpeterianos -en oposición a las prácticas rentistas-, que demanden la asistencia de mano de obra calificada para su ejecución.

Asimismo, en tanto se pretenda avanzar sobre las disparidades existentes en el interior de los espacios nacionales, resulta imperioso que la ubicación espacial de este tipo de actividades no esté concentrada en las regiones centrales. El emplazamiento en zonas periféricas de actividades industriales de creciente sofisticación-vía incorporación de tecnología e innovación-, que emplee mano de obra calificada y se nutra de relaciones con otras empresas del mismo y de otros sectores de actividad, 
sería una herramienta estratégica para disminuir las históricas asimetrías existentes entre las distintas regiones del país, y viabilizaría un desarrollo espacialmente integrador, con verdadero alcance nacional. En otras palabras, la industrialización de las regiones periféricas de la periferia resultaría un aspecto fundamental para lograr un proceso de desarrollo, que opere en reversa, haciendo más complejas y sofisticadas las estructuras productivas locales, sobre los históricos desbalances socio-económicos y territoriales ${ }^{8}$.

La política económica argentina pos-crisis de 2001 si bien, como surge de distintos planes y programas ${ }^{9}$, ha pretendido impulsar el desenvolvimiento manufacturero en procura de lograr el crecimiento nacional, inclusivo y equilibrado, poco ha podido avanzar en la modificación de la estructura, la dinámica y la plasmación espacial del sector industrial a fin de posicionarlo como un verdadero motor del desarrollo nacional. El sector manufacturero, desde la ISI, pero crecientemente a partir de la aplicación del cambio de régimen económico a mediado de la década de 1970, presenta un marcado nivel de especialización en ramas de baja sofisticación tecnológica, dinamizadas por un cúmulo de grandes actores, dentro de estrechos límites territoriales, que generan débiles encadenamientos productivos y no demandan mano de obra calificada para su ejecución.-

A continuación, a través del análisis de estadísticas oficiales, analizamos el re-surgimiento del sector industrial en el actual escenario neo-desarrollista argentino, advirtiendo la pervivencia de muchas de las características anteriormente mencionadas, y las limitaciones que ello acarrea para mejorar las condiciones de reproducción social interna e inserción internacional.

8 Esta propuesta no desconoce los señalamientos de la nueva geografía económica acerca de la propensión de las economías capitalistas a generar procesos de aglomeración (Krugman, 1992), como tampoco ciertas ventajas asociadas a dichos procesos (Storper, 2010). Sin embargo, entiende compatible la promoción de los procesos de aglomeración con la re-instalación de la preocupación myrdaliana, sobre los efectos regresivos que acarrea la asimétrica distribución de las "causaciones acumulativas" -positivas y negativas - para enfrentar procesos de desarrollo nacional inclusivos e integrales. Para que esto último tenga lugar, se requiere una implicación estatal que potencie procesos de aglomeración regionales, al tiempo que los integre dentro de una estrategia que refuerce y cualifique el proceso de acumulación nacional de los países periféricos, en un contexto global de funcionamiento del capitalismo que continúa fomentando su dependencia y subordinación (ver Fernández, 2009; Fernández, Alfaro y Davies, 2009).

9 La apuesta al desenvolvimiento industrial para impulsar el desarrollo puede verse expresada de manera muy clara en el Plan Estratégico Industrial 2020, pero también puede advertirse de la lectura de las diferentes políticas de desarrollo productivo implementadas por el gobierno nacional a través del Ministerio de Industria (ver, por ejemplo el detalle de la Guía de Programas y Beneficios para la Industria Argentina), así como en los diferentes versiones, avances y presentaciones del Plan Estratégico Territorial (PET), implementado dentro de la órbita de la Subsecretaría de Planificación Territorial de la Inversión Pública. 
Industrialización y desarrollo en la Argentina pos-"washington consensus": un abordaje crítico desde...

\section{LA INDUSTRIA POS-CRISIS 2001. SECTORES, ACTORES Y ESPACIOS PRIVILEGIADOS DEL CRECIMIENTO INDUSTRIAL}

La evolución de la industria manufacturera argentina con posterioridad a la crisis de 2001 ha evidenciado un considerable dinamismo. Como se puede advertir en el gráfico 1, la tasa de crecimiento promedio inter-anual del sector manufacturero $(8,12$ \%) ha sido superior a la del PIB global (7,58 \%). Ello dio lugar a un reposicionamiento de la actividad industrial dentro del Valor Agregado de la economía argentina, generando, en promedio, durante el período 2002-2010 el 16,25 \% del producto, luego de haber alcanzado el piso del 15,39\% en la crisis de 2001 .

Gráfico 1. Evolución de la producción manufacturera y el PIB, 2002-2010 (índice base 2002=100)

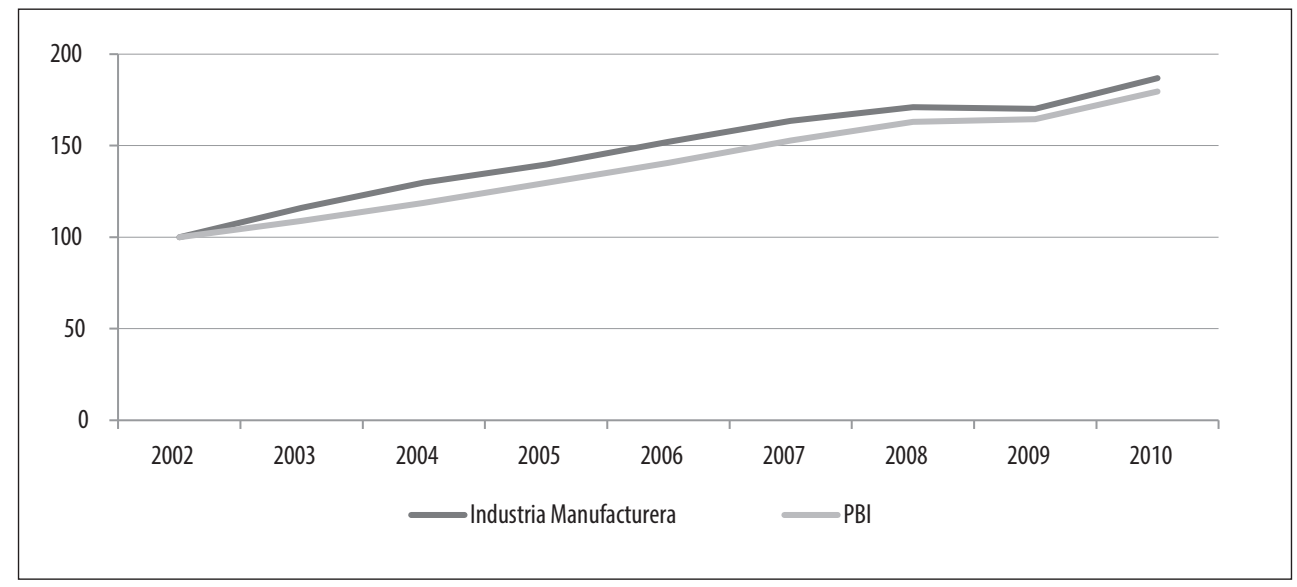

Fuente: elaboración propia sobre la base de información del INDEC, Cuentas Nacionales

No obstante, pese a esta recuperación, el sector aún no alcanza en promedio la participación que detentara dentro del PIB durante la década de 1990 (17,32 \%), período en que los efectos destructivos de las políticas neoliberales horadaron con fuerza el entramado productivo industrial. Este escenario interpela a cuestionarnos ¿sí el sector industrial, sin desconocer el importante crecimiento que ha experimentado, logró posicionarse como motor dinamizador del desarrollo del país? Es decir, ¿̇se trata de un crecimiento industrial que ha tendido a restablecer y estimular vínculos entre distintas ramas y sectores de actividad económica que hacen más complejo el entramado productivo, sobre la base del impulso al desarrollo de actividades asociadas a la generación e incorporación de innovaciones tecnológicas, que demandan para su ejecución empleo de calidad? O, por el contrario, ¿estamos ante la presencia de una recuperación industrial que presenta limitaciones estructurales en su crecimiento, al demandar débiles eslabonamientos productivos y presentar efectos limitados para mejorar los niveles de sofisticación tecnológica e incremen- 
tar la capacidad de generación de valor y de empleo de la economía? Asimismo, siguiendo los desarrollos teórico-analíticos presentados en el primer punto, cabe interrogarse: ¿qué tan nacional ha sido la recuperación de la actividad industrial? ¿Ha sido el crecimiento manufacturero un motor dinamizador de los entramados productivos a lo largo y a lo ancho del país? ¿Ha impulsado a un desarrollo territorial más equilibrado?, o, por el contrario, ¿̇u dinamismo presenta limitados efectos para revertir las históricas asimetrías territoriales?

Para procurar dar respuesta a estos interrogantes, a continuación, profundizaremos en el análisis de a) las principales actividades dinamizadoras de la producción industrial, b) las características estructurales de los actores encargados de su avance y las dinámicas de comportamiento por ellos desplegadas, así como de c) la distribución territorial de las manufacturas en argentina durante el período 2002-2010.

Cuando analizamos la composición intra-sectorial de las manufacturas, podemos observar que las ramas de alimentos y bebidas, producción de sustancias químicas; metales comunes y derivados del petróleo ocupan un lugar central dentro del Producto Industrial. Como resulta del cuadro 1, estas actividades representaban, para el año 2010, más de la mitad (el 56 \%) del producto manufacturero de la economía. Este dato pone de manifiesto la fuerte especialización del sector en actividades que sustentan su competitividad en ventajas comparativas asociadas a la explotación de recursos naturales, que se caracterizaron por presentar un reducido dinamismo para hacer más complejo el entramado productivo, desarrollar innovaciones y generar de empleo de calidad (Azpiazu y Schorr, 2010).

Si continuamos analizando el cuadro 1, la importante participación de la rama automotriz (11,1 \% del producto industrial para el año 2010) pareciera poner en cuestión la afirmación que hicimos en el párrafo anterior. Pero, al estudiar la particular dinámica de dicha actividad, no hacemos sino reafirmar las características de especialización rentística que presenta el sector. El crecimiento de la rama automotriz ha respondido, en gran medida, a un régimen especial de promoción establecido en la década de 1990, que la ha provisto, a través de protección arancelaria y aranceles preferenciales para la importación de bienes finales, insumos y piezas, de una ventaja comparativa institucional de privilegio (Azpiazu, Basulado y Schor, 2001; Azpiazu y Schorr, 2010; Schorr, 2004). La protección frívola -siguiendo la terminología de Fajnzylber (1983) - de este régimen -en la medida en que no establece mayores condicionamientos en términos de generación de valor y desarrollos tecnológicos locales-, si bien ha permitido dinamizar la actividad automotriz en la década de 1990 -y continúa haciéndolo en la actualidad ${ }^{10}$-, también ha contribuido

10 Luego de la crisis de 2001 el régimen de promoción sólo sufrió ligeras modificaciones que no fueron suficientes para superar el carácter "frívolo" de la protección, e incentivar prácticas tendientes a 
Industrialización y desarrollo en la Argentina pos-“washington consensus": un abordaje crítico desde...

a obturar el desarrollo de encadenamientos productivos y capacidades tecnológicas locales, convirtiendo a las empresas del sector en meras ensambladoras de partes y componentes importados.

\section{Cuadro 1. Evolución de la participación de las distintas ramas industriales dentro del producto bruto industrial (2001-2010)}

\begin{tabular}{|l|c|c|c|}
\hline \multicolumn{1}{|c|}{ Ramas industriales } & 2001 & 2007 & 2010 \\
\hline Elaboración de productos alimenticios y bebidas & 31,0 & 30 & 32,3 \\
\hline Eaboración de productos de tabaco & 3,5 & 2,7 & 2,8 \\
\hline Fabricación de productos textiles & 2,1 & 1,9 & 1,7 \\
\hline Fabricación de prendas de vestir y pieles & 1,8 & 1,5 & 1,3 \\
\hline Cuero y artículos de cuero & 2,4 & 3,4 & 3,6 \\
\hline Madera y productos de madera & 0,9 & 1 & 0,8 \\
\hline Papel y productos de papel & 2,9 & 2,6 & 2,4 \\
\hline Ediciones e impresiones & 3,4 & 3,4 & 3,1 \\
\hline Refinación de petróleo & 10,0 & 7,8 & 6,1 \\
\hline Sustancias y productos químicos & 12,3 & 11 & 12,1 \\
\hline Productos de caucho y plástico & 3,8 & 3,8 & 4 \\
\hline Otros productos minerales no metálicos & 2,0 & 2,5 & 2,3 \\
\hline Fabricación de metales comunes & 5,3 & 5,2 & 5,5 \\
\hline Productos de metal excluido maquinaria y equipo & 2,7 & 2,5 & 2,2 \\
\hline Maquinaria y equipo & 3,9 & 5,7 & 4,7 \\
\hline Maquinaria y aparatos eléctricos & 1,5 & 1,3 & 1,1 \\
\hline Aparatos de radio, TV, comunicaciones & 1,5 & 1,4 & 1,5 \\
\hline Instrumentos médicos, ópticos & 0,3 & 0,4 & 0,4 \\
\hline Vehículos automotores & 7,3 & 10,7 & 11,1 \\
\hline Otros equipos de transporte & 0,4 & 0,5 & 0,3 \\
\hline Otras manufacturas & 1,2 & 0,9 & 0,7 \\
\hline Totales & 100 & 100 & 100 \\
\hline
\end{tabular}

Fuente: elaboración propia sobre la base de información de Schorr $(2004 ; 2012)$

Estas ramas industriales, además de ampararse en ventajas comparativas estáticas -ya sean naturales o institucionales de privilegio- para su desarrollo, presentan efectos limitados para hacer más complejo y sofisticado la actividad manufacturera, así como para incrementar la capacidad de generación de valor agregado y de empleo

sofisticar y complejizar su desenvolvimiento sobre la base de la incorporación de progreso técnico e innovaciones (Castells y Schorr, 2013). 
en el sector. La escasa capacidad para a) desarrollar encadenamientos productivos - por estar concentradas en los primeros eslabones de las cadenas de producción o por su propensión ensambladora-, así como para b) impulsar la generación endógena de progreso técnico e innovaciones - por los comportamientos rentistas en los que se amparan- no las habilita a convertirse en motores propulsores de una industria endógena, sofisticada y compleja (Azpiazu y Schorr, 2010), que permita morigerar el diferencial de productividad e ingreso que existe con los países centrales.

Por otra parte, estas actividades manufactureras presentan un elevado grado de concentración en un reducido grupo de actores: grandes empresas, en su mayoría propiedad de capitales extranjeros ${ }^{11}$, que detentan posicionamientos monopólicos u oligopólicos en los mercados locales (Azpiazu y Schorr, 2010; Rougier y Schorr, 2012), por lo que no presentan mayores incentivos para incrementar su performance a través de prácticas innovadoras-schumpeterianas.

Según datos de la Encuesta de Grandes Empresas (ENGE) realizada por el INDEC, las grandes empresas manufactureras que se desempeñan en las ramas de alimentos, bebidas y tabaco, producción de combustibles, químicos y plásticos y maquinaria, equipos y vehículos -en la que el sector automotriz ocupa un lugar relevante- tienen una gravitación muy significativa dentro del producto bruto industrial. El valor agregado (VA) generado por las grandes empresas localizadas en estas ramas industriales ha significado, en promedio, para el interregno 2002-2010 el $44,1 \%$ del producto sectorial (cuadro 2).

Cuadro 2. Evoluciones de la participación de las empresas manufactureras del ENGE, total y por actividad, del valor agregado sectorial (2002-2010)

\begin{tabular}{|c|c|c|c|c|c|}
\hline Periodo & $\begin{array}{c}\text { Industria } \\
\text { manufacturera }\end{array}$ & $\begin{array}{c}\text { Alimentos, bebidas } \\
\text { y tabaco }\end{array}$ & $\begin{array}{c}\text { Combustibles, } \\
\text { químicos y plásticos }\end{array}$ & $\begin{array}{c}\text { Maquinarias, } \\
\text { equipos y vehículos }\end{array}$ & $\begin{array}{c}\text { Resto } \\
\text { industria }\end{array}$ \\
\hline 2002 & $55,52 \%$ & $19,57 \%$ & $21,73 \%$ & $3,12 \%$ & $11,09 \%$ \\
\hline 2003 & $50,16 \%$ & $18,49 \%$ & $20,55 \%$ & $2,17 \%$ & $8,96 \%$ \\
\hline 2004 & $52,54 \%$ & $18,00 \%$ & $20,19 \%$ & $3,16 \%$ & $11,18 \%$ \\
\hline 2005 & $53,91 \%$ & $17,75 \%$ & $21,02 \%$ & $4,19 \%$ & $10,95 \%$ \\
\hline 2006 & $53,68 \%$ & $17,96 \%$ & $20,04 \%$ & $4,83 \%$ & $10,85 \%$ \\
\hline 2007 & $57,54 \%$ & $21,84 \%$ & $19,61 \%$ & $5,70 \%$ & $10,39 \%$ \\
\hline 2008 & $57,27 \%$ & $21,18 \%$ & $21,37 \%$ & $5,30 \%$ & $9,43 \%$ \\
\hline 2009 & $50,11 \%$ & $21,52 \%$ & $17,27 \%$ & $4,01 \%$ & $7,31 \%$ \\
\hline 2010 & $54,96 \%$ & $22,70 \%$ & $18,29 \%$ & $5,55 \%$ & $8,43 \%$ \\
\hline
\end{tabular}

Fuente: Elaboración propia con base en datos de INDEC, ENGE

11 Si bien las estadísticas de la ENGE no brindan información diferenciada sobre el tipo de actividad y el origen del capital de las firmas, la tendencia a la "extranjerización" del conjunto de las empresas del panel, dentro de las cuales las manufactureras ocupan el lugar más relevante, nos permitiría inferir que las mismas no se encuentran exentas de tal tendencia. 
Industrialización y desarrollo en la Argentina pos-"washington consensus": un abordaje crítico desde...

Si bien el VA generado por estas empresas manufactureras de la ENGE, asociadas a la explotación de ventajas comparativas naturales o institucionales de privilegio -como el caso de la industria automotriz-, como se ha señalado en el párrafo anterior, es importante dentro del producto bruto industrial, la capacidad de agregación de valor de este tipo de empresas es reducida. El diferencial entre el VBP y el VA ${ }^{12}$ de las grandes empresas manufactureras en estas ramas industriales es muy marcado; el cociente VA/VBP registró un valor promedio del $29 \%$ para el período 2002-2010 (cuadro 3). Además, en tanto existe evidencia empírica de que gran parte de los insumos de los sectores en los que priman las grandes empresas industriales son bienes importados con tecnología incorporada (Azpiazu y Schorr, 2010), estas estadísticas permitirían reforzar la apreciación sobre el escaso virtuosismo de este tipo de actividades y actores en la generación de encadenamientos productivos y desarrollos tecnológicos endógenos, con las restricciones que ello acarrea para el crecimiento de la producción y el empleo en otras ramas industriales y/o sectores económicos relacionados.

\section{Cuadro 3. Evolución de la relación VA/VBP de las distintas ramas industriales dentro de las empresas manufactureras que integran el panel de la ENGE (2002-2010)}

\begin{tabular}{|l|c|c|c|c|c|c|c|c|c|}
\hline \multicolumn{1}{|c|}{ Ramas de actividad } & 2002 & 2003 & 2004 & 2006 & 2006 & 2007 & 2008 & 2009 & 2010 \\
\hline $\begin{array}{l}\text { Alimentos, bebidas y } \\
\text { tabaco }\end{array}$ & $30 \%$ & $31 \%$ & $30 \%$ & $31 \%$ & $31 \%$ & $32 \%$ & $31 \%$ & $35 \%$ & $34 \%$ \\
\hline $\begin{array}{l}\text { Combustibles, quími- } \\
\text { cos y plásticos }\end{array}$ & $36 \%$ & $35 \%$ & $34 \%$ & $33 \%$ & $33 \%$ & $32 \%$ & $36 \%$ & $33 \%$ & $33 \%$ \\
\hline $\begin{array}{l}\text { Maquinarias, equipos y } \\
\text { vehículos }\end{array}$ & $24 \%$ & $20 \%$ & $20 \%$ & $22 \%$ & $21 \%$ & $22 \%$ & $22 \%$ & $20 \%$ & $20 \%$ \\
\hline Resto industria & $40 \%$ & $37 \%$ & $41 \%$ & $39 \%$ & $37 \%$ & $36 \%$ & $35 \%$ & $37 \%$ & $36 \%$ \\
\hline
\end{tabular}

Fuente: Elaboración propia con base en datos de INDEC, ENGE

Los datos analizados permitirían inferir que, por el momento, no se han advertido cambios en el tejido industrial que contribuyan a dinamizar un crecimiento inclusivo de la Argentina. Las actividades manufactureras más relevantes, así como las características estructurales y la dinámica de comportamiento de los principales actores económicos que comandan el actual proceso de industrialización, tienden a alimentar una especialización rentista del sector, que poco contribuye a incrementar su grado sofisticación, nivel de complejidad y capacidad de generar valor agregado y empleo de calidad, de modo tal de convertirlo en un vehículo estratégico de desarrollo.

12 Conformado por el consumo intermedio de bienes y/o insumos que no son producidos por las propias empresas. 
Ahora bien, el escaso virtuosismo de la actividad industrial como dinamizadora de un crecimiento económico con inclusión -tanto al nivel actoral como al espacial- que viabilice el desarrollo se refuerza cuando analizamos el desenvolvimiento territorial de la misma.

Como resulta del gráfico 2, la región central del país -asociada a la zona pampeana ${ }^{13}$ - aglutina, y de manera creciente, gran parte de la producción manufacturera. Para el periodo $2002-2010^{14}$ generó más del 80 \% de la producción industrial, en tanto las regiones periféricas - asociadas a las áreas extra-pampeanas- solo aportan, en promedio, para el interregno considerado, el $19 \%$ del VA del sector.

Gráfico 2. Evolución de la participación del producto industrial pampeano y extra-pampeano dentro del producto industrial nacional (2002-2010)

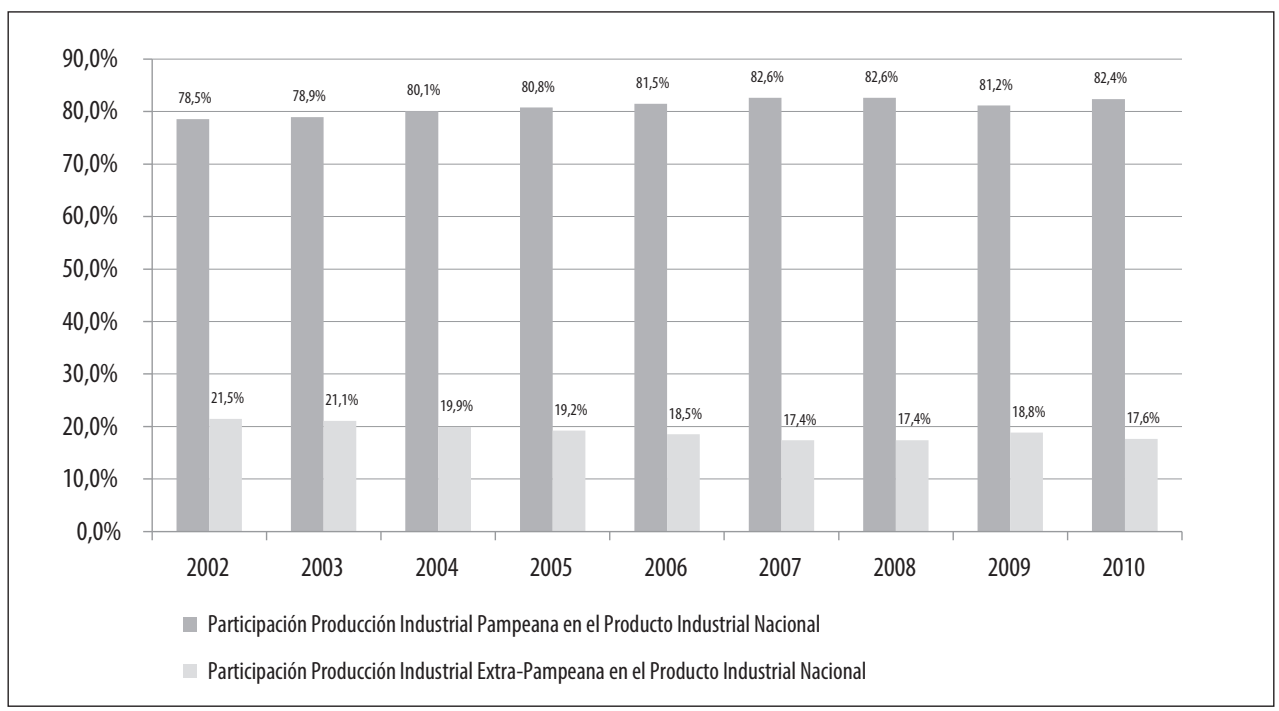

Fuente: elaboración propia con base en información del CEP. Ministerio de Industria de la Nación

Si bien esta distribución regional de la producción industrial no resulta extraña en un país como Argentina, en el que el grueso del producto es generado en las provincias de la región central -para el periodo 2002-2010 estas provincias fueron

13 Incluimos aquí a la Ciudad Autónoma de Buenos Aires, y a las provincias de Buenos Aires, Córdoba y Santa Fe; en tanto el resto de las provincias argentinas quedan incluidas dentro del área extra-pampeana.

14 Las Estadísticas Oficiales presentan datos de Producto para la gran mayoría de las provincias hasta el año 2006. Para poder extender el análisis de los PBG hasta 2010 realizamos una estimación de la evolución de la producción manufacturera de las diferentes provincias del país en función del método de mínimos cuadrados (las Provincias de Catamarca; La Pampa, Salta y Santiago del Estero, quedaron fuera de la estimación porque la bondad del ajuste no era buena). 
responsables del $75 \%$ del $\mathrm{PIB}^{15}$ - (gráfico 3), es para destacar que el grado de concentración de la actividad manufacturera es superior al del producto. La diferencial tasa de crecimiento de la industria entre las regiones centrales y las periféricas poscrisis de 2001 permite explicar esta tendencia a la hiperconcentración manufacturera. Como puede advertirse al observar el gráfico 4, el crecimiento de la producción industrial dentro de la región central fue más agudo -con tasas que superan el $9 \%$ interanual- que el de las provincias de la periferia -cuyo crecimiento alcanzó una tasa promedio del 6,22 \% interanual-. Vemos, así, cómo la dinámica espacial del desarrollo industrial contemporáneo está lejos de contribuir a una distribución más equilibrada de la manufactura en las diferentes regiones del país que permita un desarrollo nacional espacialmente más integrado.

Gráfico 3. Evolución de la participación del producto bruto pampeano y extra-pampeano y del PIB (2002-2010)

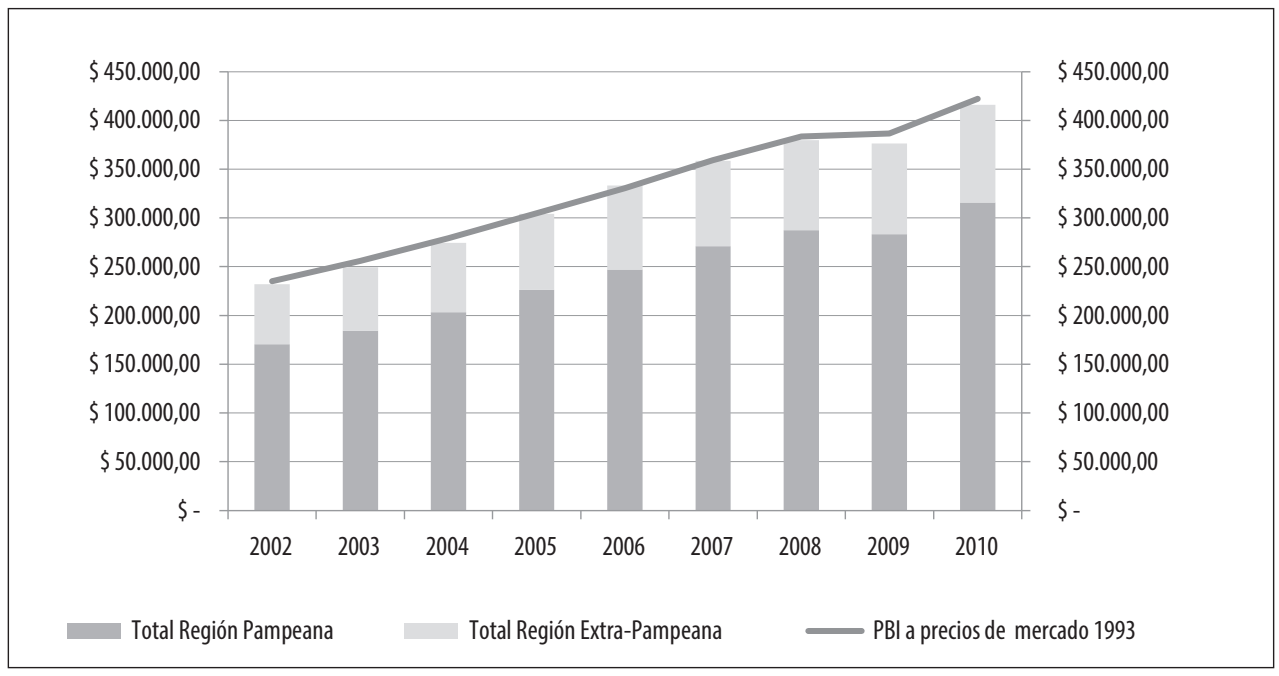

Fuente: elaboración propia con base en información del CEP del Ministerio de Industria de la Nación y de la Dirección de Cuentas Nacionales del INDEC

Por lo tanto, además de contar con un tejido industrial en el que las principales actividades manufactureras y las características estructurales y la dinámica de comportamiento de los actores económicos que las dinamizan tienden a configurar un sector con escasa capacidad de generar valor y empleo de calidad, limitada potencialidad para desarrollar innovaciones y progresos tecnológicos y debilidad a

15 Para calcular estas participaciones también recurrimos a la proyección de la evolución del Producto Bruto Provincial, por la falta de estadísticas actualizadas, para gran parte de las provincias argentinas entre 2006 y 2010; pero, aquí, sólo quedaron fuera de la proyección, por falta de bondad del ajuste, Catamarca y La Pampa. 
la hora de establecer encadenamientos con el resto de los actores productivos, nos encontramos con que el escaso virtuosismo de un sector industrial que presenta dichas características se encuentra territorialmente concentrado, lo que no permite convertirlo en un verdadero vehículo de un crecimiento económico dinámico y sostenible, con inclusión -socio-espacial-que viabilice el desarrollo.

Gráfico 4. Evolución del producto industrial pampeano y extra-pampeano (2002-2010)

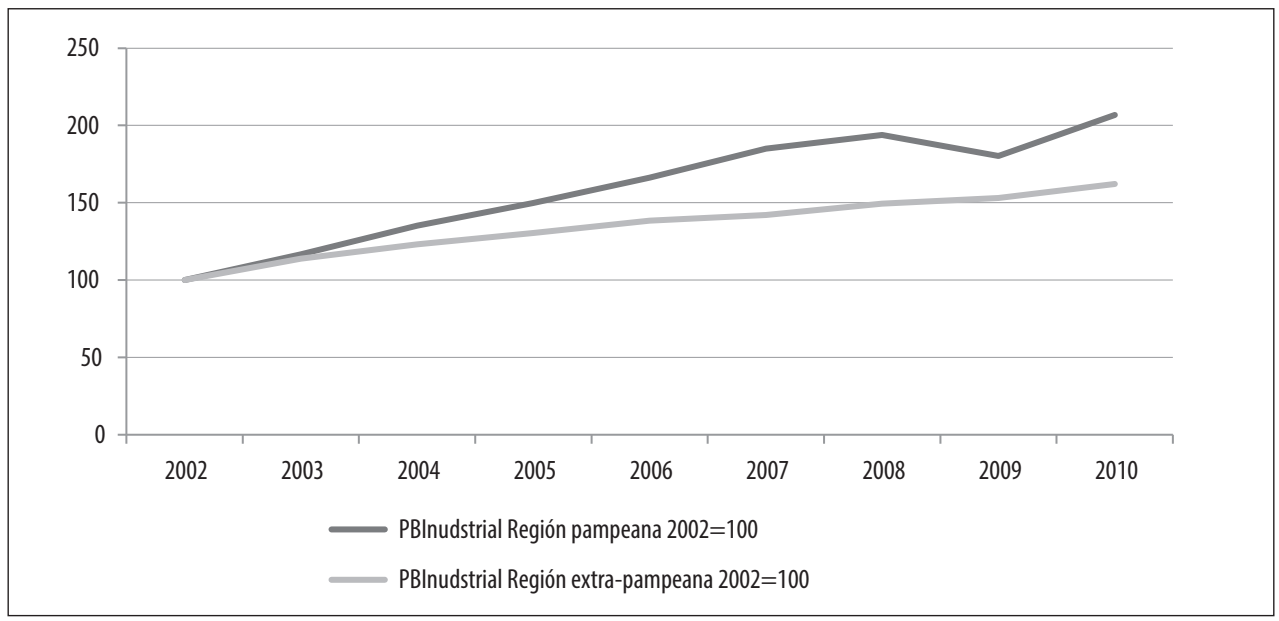

Fuente: elaboración propia con base en información del CEP del Ministerio de Industria de la Nación

\section{CONSIDERACIONES FINALES}

Producto de lo analizado a lo largo del trabajo, transcurrida en la Argentina ya más de una década desde la crisis de 2001, la pretensión neo-desarrollista de colocar a la industria como eje dinamizador del desarrollo nacional contrasta con efectos que no parecieran orientarse a la consecución de tal objetivo.

En el sector industrial las actividades de mayor peso son aquellas desarrolladas al amparo de las ventajas comparativas estáticas -asociadas a los recursos naturales y/o a ventajas institucionales de privilegio-, que no resultan claves para la formación de una estructura industrial sofisticada y compleja que permita generar, de manera dinámica y sostenible, valor agregado y empleo de calidad, debido a la limitada capacidad que presentan para desarrollar encadenamientos productivos, y procesos de innovación endógenos.

Por otra parte, estas actividades industriales presentan un elevado grado de concentración en un reducido grupo de actores: grandes empresas -en su mayoría de capital extranjero-. Dichos actores, en virtud de sus posicionamientos mono/ oligopólicos, que los habilitan para obtener rentas de privilegio, han evidenciado 
un escaso desarrollo de prácticas innovadoras y han demostrado una limitada capacidad para estimular encadenamientos productivos que involucren a actores locales. En otras palabras, el comportamiento de los grandes actores concentrados, en el escenario argentino está asociado a prácticas de tipo rentista que refuerzan el escaso virtuosismo de las actividades manufactureras en que se desempeñan, y limitan las posibilidad de posicionar a la industria nacional como motora de un crecimiento con inclusión -socio-económico y espacial-.

El escenario resulta aún más alarmante cuando se observa la hiperconcentración de la actividad manufacturera en la región central -pampeana- de país. Como se ha planteado en el desarrollo del trabajo, avanzar en un desenvolvimiento industrial más equilibrado al nivel espacial se presenta como una necesidad para viabilizar un proceso de desarrollo que, desde la complejidad y sofisticación de las estructuras productivas locales, opere en reversa sobre los históricos desbalances socio-económicos y territoriales de la Argentina.

A partir de este estado de situación, podemos señalar que el desarrollo industrial poscrisis de 2001 se encuentra lejos de generar un proceso de industrialización -sobre la base de la incorporación de progreso técnico en el sector manufactureroque permita incrementar la productividad de la economía y adquirir competitividad internacional en los segmentos de mayor agregación de valor de la producción manufacturera global, de modo de mejorar las condiciones de reproducción social de sus habitantes a lo largo y a lo ancho del territorio. Antes bien, podemos considerar que el mismo responde a un episodio de crecimiento desequilibrado del sector que margina a múltiples actores socio-económicos y concentra su dinamismo en estrechos márgenes territoriales.

Ante la advertencia de esta realidad, el desafío que se presenta a la política industrial neo- desarrollista está orientado a saldar dos cuentas pendientes: una a) asociada a la complejidad y sofisticación del sector manufacturero industrial nacional de modo tal que su crecimiento viabilice un cambio estructural, y otra b) vinculada al emplazamiento territorial de dicha industrialización, para que, a partir de la misma, no solo se puedan revertir las asimetrías de productividad e ingreso existentes con los países centrales, sino, también, las que existen entre las regiones centrales y periféricas de un mismo país, y se pueda propiciar un desarrollo verdaderamente nacional.

\section{BIBLIOGRAFÍA}

Altenburg, T. (2011). Industrial policy in developing countries. Overview and lessons from seven country cases. Deutsches Institut für Entwicklungspolitik. Discussion Paper. 
Amsden, A. (2004). La sustitución de importaciones en las industrias de alta tecnología: Prebisch renace en Asia. CEPAL, Vol.82, p. 75-90.

Arceo, E. (2005). El impacto de la globalización en la periferia y las nuevas y viejas formas de dependencia en América Latina. Cuadernos del Cendes, Vol.22, p.27-63.

Arceo, E. (2011). El largo camino a la crisis. Centro, periferia y transformaciones en la economía mundial. Buenos Aires: Cara o Ceca.

Arrighi, G., Silver, B., y Brewer, B. (2003). Industrial Convergence, Globalization, and the Persistence of North-South Divide. Studies in Comparative International Development, p.3-31.

Azpiazu, D. (1997). El nuevo perfil de la elite empresarial. Concentración del poder económico y beneficios extraordinarios. Realidad Económica, 145p.

Azpiazu, D., Basulado, E., y Schorr, M. (2001). La industria argentina durante los años noventa: profundización y consolidación de los rasgos estructurales centrales de la dinámica sectorial post-sustitutiva. FLACSO-Área de Economía y Tecnología.

Azpiazu, D., y Schorr, M. (2010). Hecho en Argentina. Industria y economía, 1976-2007. Buenos Aires: Siglo XXI Editores.

Bell, D. (1973). The Coming of Post-Industrial Society: A Venture in Social Forecasting. United States of America: Basic Books.

Bresser- Pereira LC. (2007) Estado y mercado en el nuevo desarrollismo. En: Nueva Sociedad, 210, p. 110-125.

Bresser-Pereira LC. (2006) El nuevo desarrollismo y la ortodoxia convencional. En: ECONOMÍAUNAM, 4, p. 7-29.

Cao, H., y Vaca, J. (2006). Desarrollo regional en la Argentina: la centenaria vigencia de un patrón de asimetría territorial. Eure, XXXII, p.95-111.

Castells, M. J., y Schorr, M. (2013). ¿Sustitución de importaciones en la posconvertibilidad? En M. Schorr (Ed.), Argentina en la posconvertibilidad: ¿̇desarrollo o crecimiento industrial? Estudios de economía política. Buenos Aires: Miño y Dávila.

CEPAL. (2012). Cambio estructural para la igualdad. Una visión integrada del desarrollo. Santiago de Chile: CEPAL.

Cohen, S., y Zysman, J. (1987). Manufacturing Matters. The myth of the post-industrial economy. New York: Basic Books.

Coatz, D., y Kosacoff, B. (2012). Fortalezas y desafíos de la política económica argentina en el marco de la crisis. La necesidad de consolidar una política industrial integral. Proyección.

De Mattos, C. (1979). Crecimiento y concentración espacial en América Latina: algunas consecuencias. Eure, Vol. 6, p.9-21. 
Industrialización y desarrollo en la Argentina pos-" washington consensus": un abordaje crítico desde...

Evans, P. (2004). Developmental as Institutional Change: The Pitfalls of Monocropping and the Potentials of Deliberation. En: Studies in Comparative International Development, Vol. 38, No. 4, p.30-52.

Fanelli, J. M. (2012). La Argentina y el desarrollo económico del siglo XXI ¿cómo pensarlo?, ¿qué tenemos?, ¿qué necesitamos? Buenos Aires: Siglo XXI Editores.

Fajnzylber, F. (1983). La industrialización trunca de América Latina. México: Editorial Nueva Imagen.

Fajnzylber, F. (1992). Industrialización en América Latina. De la caja negra al casillero vacío. Nueva Sociedad, Vol. 118, p.21-28.

Fernández, V. (2009). ¿Qué desarrollo regional para qué desarrollo nacional? Desafíos para una Argentina posneoliberal, Realidad Económica, 242p.

Fernández, V.; Alfaro, B.; Davies, C. (2009). Aglomeraciones productivas y territorio: en busca de una manera más holística de entender sus contribuciones al desarrollo, Economía, Sociedad y Territorio, Vol. 31, p. 629-680.

Fernández, V y Lauxmann, C. (2014) ¿Cuál(es) camino(s) conduce(n) a Roma? Estado y políticas industriales en los desafíos del desarrollo latinoamericano.Cuadernos del CENDES, Vol. 86, p. 49-72.

Ferrer, A. (2007). La Economía Argentina. Desde sus orígenes hasta principios del siglo XXI. Buenos Aires: Fondo de Cultura Económica.

Furtado, C. (1974) El modelo brasileño. Graham, A. (traduc.). En El mito del desarrollo económico y el futuro del tercer mundo. Buenos Aires: Ediciones Periferia.

Gaitán, F. (2014) Auge, ocaso y resurgimiento de los estudios sobre desarrollo en América Latina, CEPAL- Documento de Proyecto.

Gurrieri, A. (2011). O Manifesto Latino-Americano e Outros Ensaios. Rio de Janeiro: Contraponto.

Greenwald, B., y Stiglitz, J. (2006). Helping Infant Economies Grow: Foundations of Trade Policies for Developing Countries. New Developments in Macroeconomics, Vol. 96, p. 141-146.

Hausmann, R. y Rodrik, D. (2003). Economic development as self-discovery. Journal of Development Economics, Vol. 72. p. 603-633.

Hausmann, R, Rodrik, D. y Sabel, C. (2008) Reconfiguring industrial policy: A Framework with an application to South Africa. CID Working Paper 168p.

Helper, S., Krueger, T. y Wial, H. (2012). Why Does Manufacturing Matter? Which Manufacturing Matters? A Policy Framework. Metropolitan Policy Program at Brookings..

Kutznets, S. (1971). Economic Growth Of Nations; Total Output And Production Structure. Massachussetts: Harvard University Press. 
Krugman, P. (1992) Geografía y Comercio. Barcelona: Antonio Boschi Editor

Manzanal, M. (1995). Globalización y ajuste en la realidad regional argentina: reestructuración o difusión de la pobreza? Realidad Económica, 134p.

MPFIPS. (2006). Argentina 2016. Política y Estrategia Nacional de Desarrollo y Ordenamiento Territorial.

Ministerio de Industria (2012). Plan estratégico industrial. Argentina.

Myrdal, G. (1959) Teoría Económica y regiones subdesarrolladas. México: Fondo de Cultura Económica

Nochteff, H. (1998). Neoconservadurismo y subdesarrollo. Una mirada de la economía argentina.

En H. Nochteff (Ed.), La economía argentina a fin de siglo: fragmentación presente y desarrollo ausente. Buenos Aires: FLACSO-EUDEBA.

Prebisch, R. (1983). Cinco etapas de mi pensamiento sobre el desarrollo. El Trimestre Económico, Vol. 2, p. 1077-1096.

Prebisch, R. (1986). El desarrollo económico de la América Latina y algunos de sus principales problemas. Desarrollo Económico, Vol. 26, p. 479-502.

Prebisch, R. (2008). Hacia una teoría de la transformación. Revista de la CEPAL.

Rapoport, M. (2000). Historia Económica, Política y Social de la Argentina (1880-2000). Buenos Aires: Ediciones Macchi.

Reiner, C. y Staritz, C. (2013). Private sector development and industrial policy: Why, how and for whom? Österreichische Entwicklungspolitik.

Rodrik, D. (2004). Industrial Policy for the Twenty-First Century. CEPR Discussion Paper, No. 4767.

Rofman, A. (1999). Economías regionales. Modernización productiva y exclusión social en las economías regionales. Realidad Economica, Vol. 162, p. 107-136.

Rougier, M., y Schorr, M. (2012). La industria en los cuatro peronismos: estrategias, políticas y resultados. Buenos Aires: Capital Intelectual.

Schorr, M. (2004). Industria y nación. Poder económico, neoliberalismo y alternativas de reindustrialización en la Argentina contemporánea. Buenos Aires: Edhasa.

Schorr, M. (2012). Argentina: ¿nuevo modelo o viento de cola? Una caracterización en clave comparativa. Nueva Sociedad, Vol. 237, p. 114-127.

Schvarzer, J. (1996). La industria que supimos conseguir. Una historia político-social de la industria argentina. Buenos Aires: Planeta.

Sunkel, O. (1970). Desarrollo, subdesarrollo, dependencia, marginación y desigualdades espaciales; hacia un enfoque totalizante. Eure, Vol. 1, p.13-49.

Storper, M. (2010). Agglomeration, Trade and Spatial Developmente: Bringing dynamics back in, Journal of Regional Science, Vol. 50, p. 313-342.

Wade, R. (2012). Return of industrial policy? International review of applied economics, Vol. 26, p. 223-239. 